\title{
REGULATORY INSTRUMENTS AND THEIR EFFECTS ON INVESTMENT BEHAVIOR ${ }^{1}$
}

\author{
Phil Burns and Christoph Riechmann
}

Frontier Economics

\author{
Contact Details: \\ Frontier Economics \\ 71 High Holborn \\ LONDON \\ WC1V 6DA
}

Tel: 00442070317000

Fax: 00442070317001

E-mail: philip.burns@frontier-economics.com

World Bank Policy Research Working Paper 3292, April 2004

The Policy Research Working Paper Series disseminates the findings of work in progress to encourage the exchange of ideas about development issues. An objective of the series is to get the findings out quickly, even if the presentations are less than fully polished. The papers carry the names of the authors and should be cited accordingly. The findings, interpretations, and conclusions expressed in this paper are entirely those of the authors. They do not necessarily represent the view of the World Bank, its Executive Directors, or the countries they represent. Policy Research Working Papers are available online at http://econ.worldbank.org.

1 The authors are grateful to Antonio Estache and two referees for comments and discussions, as well as to participants of a WBI sponsored workshop on infrastructure regulation. The corresponding author is Phil Burns at the email address: phil.burns@frontier-economics.com. 


\title{
REGULATORY INSTRUMENTS AND THEIR EFFECTS ON INVESTMENT BEHAVIOR
}

\begin{abstract}
:
Regulatory instruments have long been understood to have a powerful effect on investment, and part of the motivation for introducing higher-powered regulatory regimes and contracts was to reduce incentives for inefficiency and over-investment (gold plating) inherent in cost-plus regulatory schemes. In practice, the mix of incentives and the institutional framework that make up a higher-powered regulatory regime can also lead to unintended distortions on investment behavior. In this paper we examine the key drivers of investment behavior, and provide some examples of how these drivers have affected investment in practice. We conclude with a set of key areas and inter-relationships that are at the core of a regulatory settlement, and therefore need to be designed appropriately to drive efficient investment behavior.
\end{abstract}




\section{Introduction}

In this paper, we focus on the naturally monopolistic network industries that have not, for reasons of their technology and cost structure, been exposed to the proliberalization initiatives that have usually accompanied utility sector reform. Investments are needed to develop and maintain these networks, and the investments themselves have an ongoing value for many years after the investment has been made.

While historically there have been concerns about over-investment, there is now a growing unease about under-investment. Of course investment in itself is not an objective for either producers or consumers. Producers are keen to earn returns that exceed their own cost of capital, and are interested in investment because, among other things, it can drive the value of the regulatory asset base on which the allowed returns are calculated. Consumers are primarily interested in the level of service quality. They have an indirect interest in investment because it is a key driver of quality - among other drivers. In this regard consumers favour high investments, which may serve as a leading indicator for future levels of service quality. At the same time, investment adds to the cost base that is ultimately borne by consumers. To this end consumers disfavor investment.

Neither producers (network operators) nor consumers draw direct value from investment. However, investment is a key driver of the surplus they extract from the economic activity in question. The key question we address in this paper is how to approach the task of balancing these often-diverging interests.

In this paper we examine the key drivers of investment behavior in regulatory regimes, and provide some examples of how these drivers have affected behavior in practice. We conclude with a set of key areas and inter-relationships that are at the core of a regulatory settlement, and therefore need to be designed appropriately to drive efficient behavior.

In doing so, we focus on the specific instruments used by regulators in the setting of price and quality regimes. We do not formally nest these instruments in a general model of regulatory credibility and commitment, since to do so would obscure 
some fundamental conclusions for little purpose. We do, however, draw attention to commitment problems as they arise.

\section{Investment and changing regulatory paradigms}

Incentives to over-invest and poor incentives to reduce efficiency are usually associated with low-powered regulatory regimes. Averch and Johnson (1962) show that strong incentives exist to expand the rate base if the utility was allowed a rate of return in excess of the cost of capital. This point is re-iterated by Baumol and Kleverick (1970) who add that attention should also be focused on the reduced incentives to improve overall cost efficiency under the classic US style of regulation. The massive building programs of the US utilities in the late 1960s and early 1970s tend to indicate that this effect prevailed in practice, as well as in theory. In such a world of over investment, high service quality is a (to some extent unintended) side product of low-powered regulation.

In order to eliminate these problems, either a bureaucratic regulatory procedure is required to provide regulators with the power to strike out some investments in a manner that is not opportunistic (and which therefore would not deter future efficient investment) or, if such a mechanism does not exist, regulators are in danger of signing off on investment plans in advance of the investment being made, which inevitably leads to a blurring of accountability in the management of the firm, and ongoing micro-management of the company's activities by the regulator. As such, the remedies to deal with the over-capitalization problem under low-powered incentive regimes carry significant costs of their own.

Higher-powered incentive mechanisms were developed in the 1980s outside of the United States, largely to escape from these problems. In practice, higher-powered forms of regulation raise their own specific issues with respect to investment behavior. The mix of incentives and the institutional framework that make up the overall regulatory package can lead to a variety of outcomes. The purpose of this paper is to draw out the lessons for incentive design, for both regulators and companies. 


\section{Incentive regulation and output delivery}

If the general problem with low-powered incentive regulation is that it encourages gold-plating of the system, low effort, and excessive output delivery, the problem with incentive based regulation is that it can encourage excessive cost reduction, to the detriment of the provision of output. In the United Kingdom, the first example of this was the behavior of British Telecom after privatization, which was criticized for allowing its public telephone boxes to degenerate into a state of disrepair, since it perceived no profit incentive to keep them operating normally.

Under incentive based regulation, the provision of service quality is decentralized to the business, within a framework of payments and penalties (which may be defined to a greater or lesser degree of clarity), and the monitoring of that level of service is undertaken by the regulator (to a greater or lesser degree of accuracy). Where the implied payments and penalties are low, or are unclear, it can be expected that the incentives for cost reduction will dominate the incentives for output provision. On the other hand, if the implied payments are very high, then incentives for greater service provision will dominate incentives for cost reduction. In practice, regulators should aim to balance incentives to achieve output provision that is socially acceptable, at efficient levels of cost. It is important to recognize that all regulatory regimes can be characterized in this way - it is not necessary for a formal, explicit service regime to exist for there to be incentives on the part of operators to wish to provide a certain level of service quality. For example, quality regimes could be characterized by a combination of guaranteed or minimum standards, marginal payments and penalties, and some form of conditional relationship between price control revenues and quality of service, to a greater or lesser degree of transparency.

The problem with the relationship between service quality and investment spending is that there is no doubt that the relationship exists, but that the strength of the relationship and the timing of the relationship is not well understood, either by the firm or the regulator. The concern that quality regulation seeks to address is that investment could be reduced in response to cost incentives, but the effect of this on 
quality will not be felt for a number of years, which could be beyond the horizons of the present management of the business.

Ideally, therefore, quality regulation should expose current management to the implications of its investment decisions even if these may arise in the future. This could, for example take the form of a regulatory regime based upon both a set of indicators of the current level of service quality provided by the business, and leading indicators of the level of quality that can be expected in the future, given the current state of the assets. The regulatory regime based on this information could be a mixture of price signals (fines and receipts) and discrete regulatory initiatives, such as the removal of the operator's licence.

Figure 1 illustrates a stylized regulatory regime applied to two businesses, A and $\mathrm{B}$, each with different marginal costs of quality, which is presumed to be observable on both a contemporaneous and leading indicator basis. A constant marginal payment, Y, embodied either within the price control or within a separate regulatory instrument, leads to the firms choosing the level of quality where the marginal costs and payments are equalized. Incentive regime $\mathrm{Z}$ embodies different incentives - implicitly there is a very high fine for quality levels below a certain level as the company would forego a high quality related revenue if it chose a lower quality level, which could either be a very high monetary payment, or regulatory exhortations, or the withdrawal of the operator's licence, for example. This regime encourages the companies to converge on some pre-determined, administratively set, level of quality. 


\section{Figure 1: Quality incentive schemes}

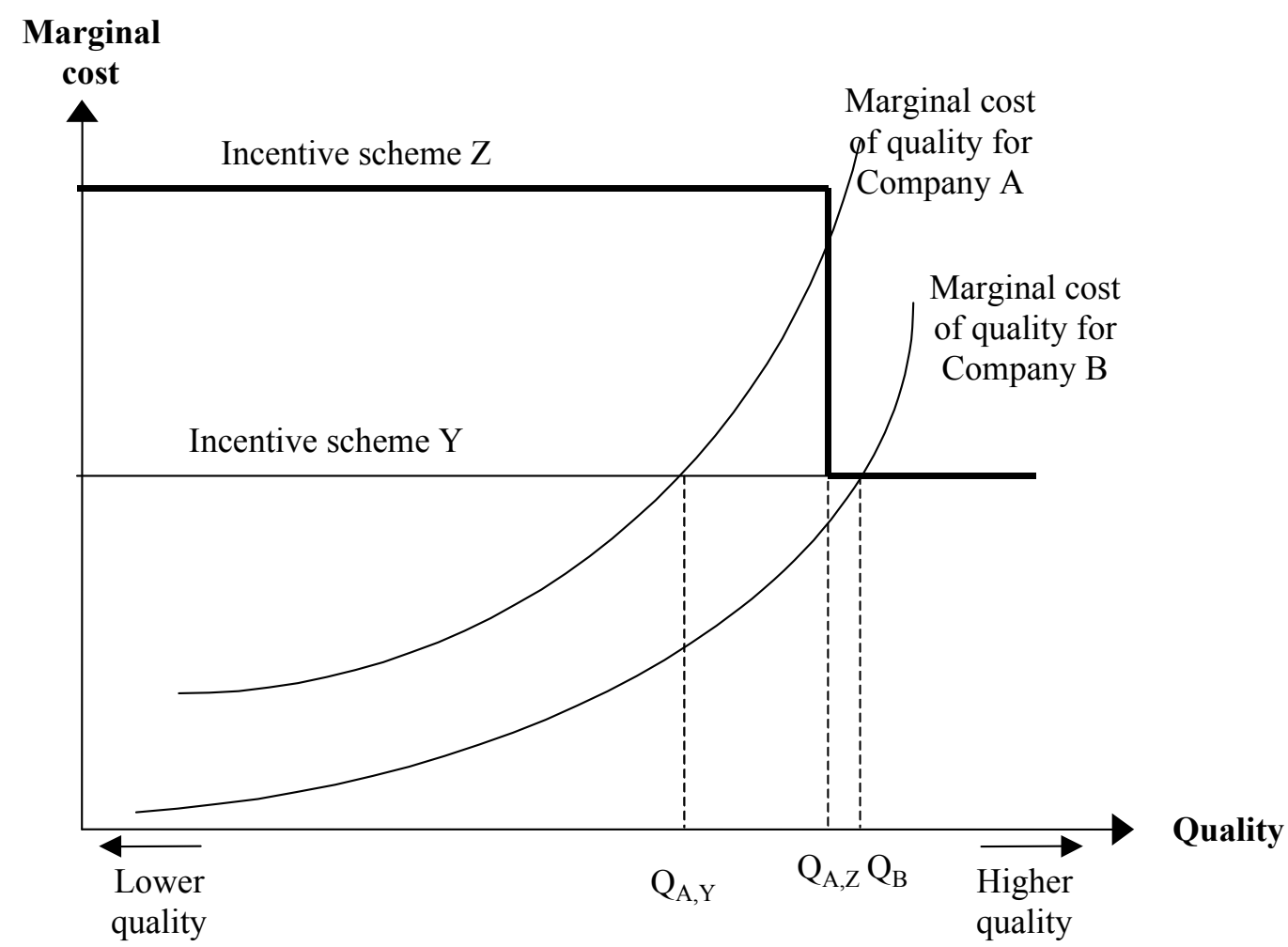

It should be acknowledged that even if a formal quality regime is not adopted, an informal regime applied within the general price control review can be characterized in precisely the same way and would require precisely the same information to implement. A regulator that sets a performance target for a business will have to permit a level of revenue through the price control that enables the business to fund the investment to meet that target, and the degree to which the revenue is conditional, either formally through the price control formula or through other regulatory actions, determines the incentive power. Consequently, the approach described here is general.

In practice, the application of this approach therefore requires a number of key pieces of information:

- $\quad$ Current indicators of quality

- $\quad$ Future indicators of quality 
- The performance targets

- The marginal cost of quality

- The explicit or implicit payment rates at different quality levels

Problems have emerged where either the implicit and explicit payment rates have been low, relative to the marginal cost of quality, and where there are either no future indicators of quality in the regime, or where indicators have existed, they are not appropriate. We discuss each in turn.

\section{Low payment rates}

Regulation in United Kingdom utility industries has typically been designed such that firms' revenues or prices are capped subject to companies meeting certain minimum quality standards. Additional incentive schemes have been put in place to provide incentives for out-performance of certain minimum standards.

In the rail sector in Britain, both the train operating companies (TOCs) and the network operator (previously Railtrack, now Network Rail) received revenue from a number of sources. TOC revenue is derived from the farebox plus any payments received from the performance regimes. Under the performance regimes, each TOC is assigned a target for reliability and punctuality, with payments made or received if the targets are not met or exceeded. Consequently, the farebox revenue is driven by growth in passenger numbers (which would be partly affected by quality), while the revenue from the performance regimes is driven by quality. The only other profit pressure that TOCs must consider in choosing their quality performance is that if quality falls to unacceptably low levels then it is at greater risk of not having its franchise to run the service renewed.

Since 1999, the rail industry has been in a state of turmoil, and it is difficult to unravel the power of different incentive effects in the overall political and economic environment. However, for three years up to 1999, the franchised TOCs operated under a system of regulation that was relatively free of these effects. The figure below indicates the financial benefit to the TOCs if they were to run a perfectly punctual and reliable service, as a proportion of their total income (as of 1998/9), given the parameters of the performance regime and the assumptions used by the Strategic Rail Authority (SRA) in evaluating the effect of performance on farebox. 
Figure 2: Maximum overall incentives towards performance as \% of total annual income

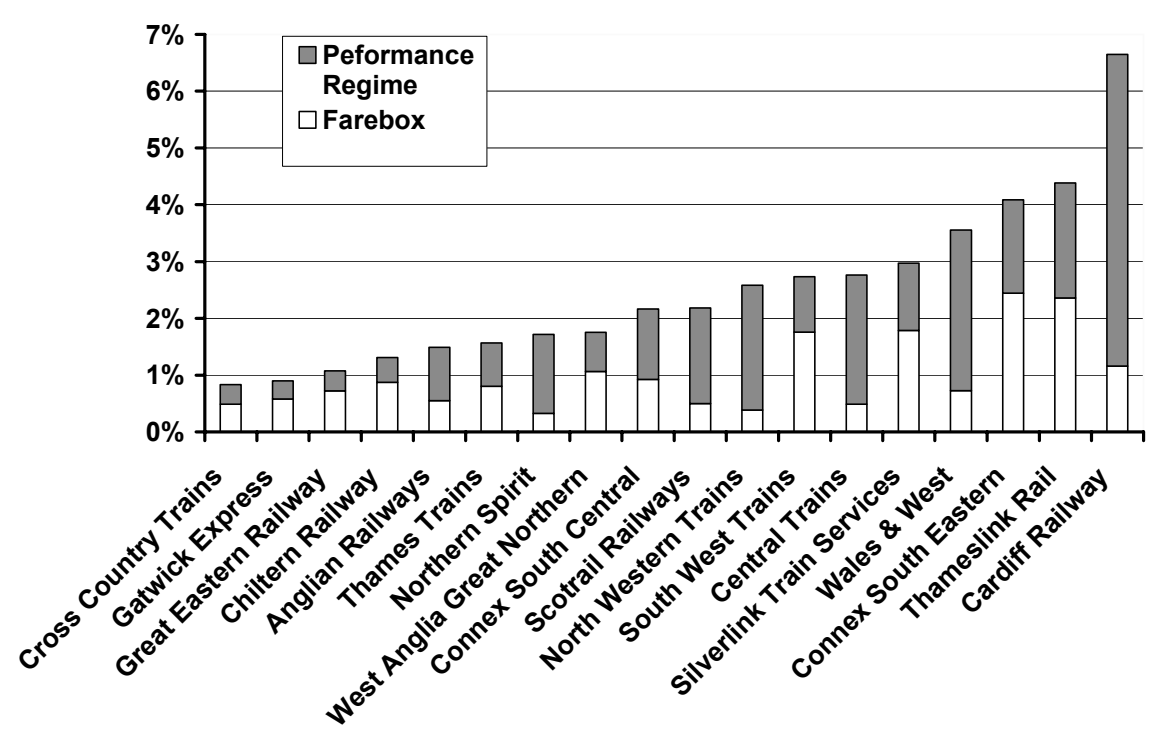

\section{Source: Frontier Economics calculations based on SRA data}

It is clear that the maximum incentive payments available represent a relatively small proportion of TOC total income (1\% to $7 \%$ varying by company), especially if the assumed farebox effect of performance fails to materialize. On the other hand, the penalties levied on the company can, in principle be much greater. This may indicate that the positive benefits an operator achieves from perfect quality are relatively low performance payments and probably a rather weak farebox effect. In contrast, the penalties for performing moderately badly are a loss of reputation and, ultimately, the loss of the franchise. In other words, it is possible that operators are incentivised to avoid extremely bad performance rather than strive for excellent performance.

The regime applied to Railtrack was somewhat different. It was a regulated network monopoly business, whose incentives to invest could expect to be driven by the performance regime specific to Railtrack (which was similar in character to the one applied to the TOCs) and the regulatory treatment of investment at the price 
control review. As far as the strength of the incentives in the regime are concerned, the maximum payout to Railtrack in 1998/9 could have been $£ 150$ m (equivalent to $6 \%$ of turnover). By far the biggest source of revenue for Railtrack was, however, the revenue from track access charges set by the Office of the Rail Regulatory (ORR), and the incentives for investment provided through the price control would swamp those provided through the performance regimes. If the regulatory regime applied to Railtrack was high-powered, with a strong emphasis on cost reduction and little monitoring of investment, then the overall regime for quality improvement could be characterized as low-powered. If on the other hand, the regulatory arrangements tended to encourage effective investment spend through effective monitoring of investment and asset quality, then the incentives to invest in quality are stronger. As it turned out, at the outset of the new regulatory arrangements, the monitoring of Railtrack's investment spend was extremely limited. The licence condition dealing with investment monitoring (section 7) was ineffectual and subsequently had to be tightened considerably. Consequently, for most of the early period after privatization, the incentives to improve quality were extremely weak compared to the incentives to cut costs, increase profitability and distribute that profit to shareholders.

The consequences of the weak regulatory regime to encourage reliability and punctuality are seen in the table below, which indicate that quality fell between 1996 and 1999. It should be noted that that the performance of TOCs is to some extent contingent on the quality performance on Railtrack (and in certain cases also on the performance of other TOCs). This issue has been addressed through a two tier regime. In the first tier the TOC is responsible for the observed level of performance. However, there is a second tier scheme through which TOCs can reclaim from Railtrack any loss in performance related payments that are the result of poor performance on the side of Railtrack. There is also the possibility that TOCs make claims against each other. 
Table 1: Average delay minutes per period

\begin{tabular}{l|c|c|c}
\hline & $\mathbf{1 9 9 6 / 9 7}$ & $\mathbf{1 9 9 7 / 9 8}$ & $\mathbf{1 9 9 8 / 9 9}$ \\
Minutes & Minutes & Minutes \\
\hline Railtrack & 560,384 & 551,836 & 609,044 \\
\hline Operator & 306,261 & 369,852 & 447,787 \\
\hline Total & 866,645 & 921,688 & $1,056,831$ \\
\hline
\end{tabular}

Source: OPRAF

\section{No future indicators of quality in the regime, or inappropriate indicators}

In the rail example given above, an additional problem with the incentive package was the absence of leading indicators of quality against which the businesses could also be judged. If indicators of the health of the network in particular had been formalized within the regulatory regime, then this would have provided an additional impetus to operate the network reliably and safely.

Where leading indicators of quality do exist (and they tend to be informal in nature), they tend to be based upon the investment that has been undertaken. This can create inadequate incentives for capital cost efficiency because regulators are attempting simultaneously to regulate costs and quality by setting a single variable: the firm's investment programme, which is seen as both a contemporaneous and leading indicator of quality. In these cases, there is evidence that network businesses are becoming more capital-intensive (and less flexible in their response to regulatory incentives) as a result. If quality can be subjected to a separate output-based regime, even a crude one, this dual treatment of capital can be avoided.

A type of future indicator scheme that relies upon information regarding the quality of the assets (as opposed to the level of investment, per se) does apply in the water sector in England and Wales. The companies must submit to the regulator satisfactory asset management plans, on which it is possible for the regulator to judge the ongoing health of the network assets. No explicit system of fines and rewards are 
based on these plans, but the regulator has powers to impose an enforcement order on a company - allowing a special administrator to be appointed to run the company - if it is failing to meet any of the conditions set out in its licence, which include the obligation to produce satisfactory periodic underground asset management plans.

\section{Quality regulation within a comparative regulatory model}

Before leaving the general question of quality regulation within an incentive based regime, it is useful to consider briefly how quality regulation sits within a comparative system of regulation. Many regulators in Europe and around the world use comparative information to inform a variety of regulatory decisions. However, quite clearly, any yardstick regime applied to cost must sit consistently with quality regulation.

First, it is well understood that firms differ by their exogenous characteristics. This has led regulators to recognize differences in price levels, whilst at the same time requiring convergence on some efficiency standard. The implication of this observation is that at one extreme price levels could converge so long as quality performance were allowed to differ, whilst at the other extreme, regulators could focus on uniform quality standards across an industry, but must be prepared to let prices differ to fund the differential costs associated with quality standardization.

These choices are illustrated in Figure 3, which represents the cost functions of network operators in a favorable environment (Company B) and in a less favorable (Company A) environment. If the regulator essentially provides each firm with the same marginal payment for quality, on the grounds that the marginal valuation of quality is broadly similar across the two areas, then quality differences will result, but prices will be converged, all else being equal. If, however, the regulator insists on a uniform quality level $\underline{Q}$, then costs and prices will vary significantly. Moreover, it is likely that if customer marginal valuations are similar, then company A will be overdelivering on quality, relative to the customers' willingness to pay, whilst company B, will be under-delivering on quality. 


\section{Figure 3: Finding the optimal level of quality}

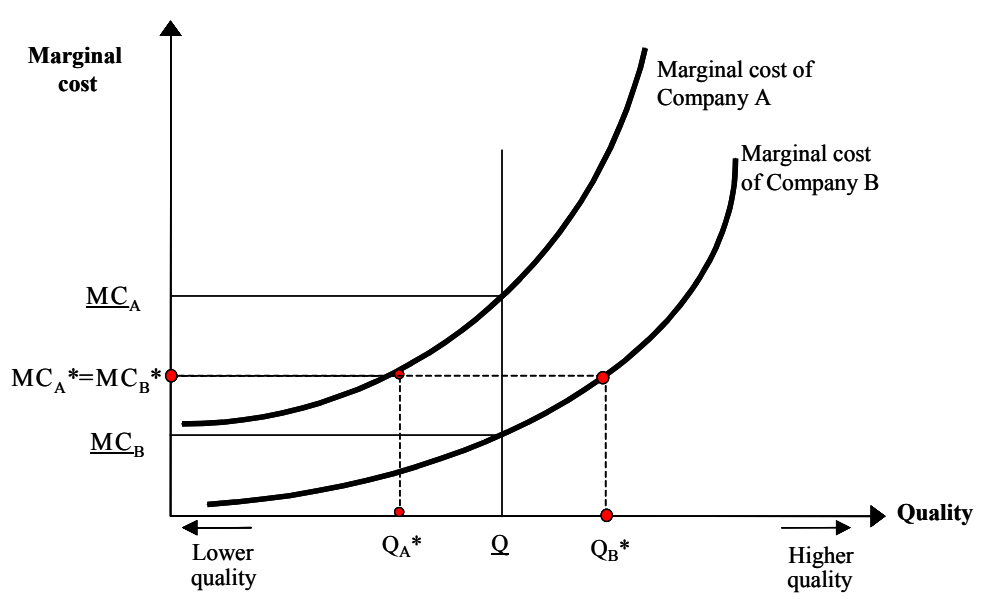

This simple example suggests the following implications for the design of quality incentive schemes:

- Where monetary incentive schemes are applied these should be differentiated to reflect local operating environments

- Unless there is compelling evidence that the marginal willingness to pay differs across companies, the emphasis should be on cost and price convergence rather than quality convergence, but within upper and lower quality bounds beyond which the payment scheme is ineffective. Otherwise there is a risk of a deterioration of quality, where the results could be either excessively high quality or unacceptably low quality

- A comparative scheme applied to both cost and quality is likely to be very complex to administer and would most likely lead to multiple equilibria, and increased uncertainty facing the operators. 


\section{Summary}

Complex incentives for quality improvements are likely to result in perverse outcomes, because of the considerable uncertainties regarding the costs and benefits of improved quality.

If the test of a quality regime is not whether it produces the "right" quality, however defined, but whether it allows high-powered incentives to reduce total costs without endangering quality provision, then such a regime can be simple yet effective.

Regulatory consistency and commitment are important. Regulated firms could take an appropriately long-term view of capital expenditure if they had the same level of confidence in the regulatory penalties or rewards for quality performance far into the future.

Regulators face institutional constraints on their ability to make binding commitments but more consistency and informal commitment to both a price-setting and quality performance regime over the longer term could help to remove concerns about short term, opportunistic, failure to deliver investment programmes. This would enable a more consistent approach to be taken between promoting operating and capital efficiency.

\section{Incentive regulation and choice of inputs}

Incentive-based regulation will typically involve the resetting of price controls at some point. At that point in time, the regulator will usually seek to transfer some of the efficiency gains made by the company to customers. The regulator is also likely to reset prices on the basis of some efficiency analysis of operating and investment costs that have previously been incurred. Both of these regulatory decisions can impart incentives to distort the business' input mix. 


\section{Treatment of efficiency savings}

Companies are rewarded for making savings compared to their operating expenditure projections. A saving in operating expenditure in any year is calculated as a reduction in the level of recurrent operating expenditure, that is, we assume that once made a saving should be maintained indefinitely. A $£ 1 \mathrm{mn}$ saving in operating expenditure has, using a $7 \%$ discount rate, a present value of $£ 14.3 \mathrm{mn}$, some proportion of which will be retained by the company.

Under most existing regulatory arrangements, companies are rewarded for making savings against their capital expenditure budgets through their RAB (regulatory asset base). For the years between price controls, prices are set on the basis of an opening value together with a stream of projected capital expenditure figures. If a regulated firm is able to save $£ 1 \mathrm{mn}$ compared to its projected investment in a given year, then it earns the rate of return plus a depreciation payment on the $£ 1$ mn saved for the years until the next price review. At each review, the RAB and depreciation payments are recalculated on the basis of actual investments, and the benefit of any capital expenditure saving passed through to customers. On this basis it is straightforward to calculate the proportion of operating and capital expenditure savings retained by the company under different regulatory retention periods. In the table below, we show illustrative calculations for a recurring operating expenditure saving, a one off capital expenditure saving and a recurring capital expenditure saving.

If both operating and capital expenditure savings are recurring then it is clear that an operating expenditure saving is more rewarding for the companies than a similar reduction in capital expenditure. However, if most capital expenditure reductions are one off, rather than recurring, while operating expenditure savings are recurring, then this conclusion no longer holds and instead we would conclude that the strength of the incentive to make efficiency savings is comparable for both operating and capital expenditure.

The nature of capital expenditure savings, when compared to operating expenditure savings that we assume to be recurring, is therefore central to determining 
whether companies need to be given stronger incentives to make capital expenditure reductions. However, it is clear that a one off reduction in operating expenditure is worth more to a regulated company than a one off reduction in capital expenditure. It is this difference in the strength of incentives that makes the capitalization of operating expenditure a profitable strategy.

Table 2: Shares of a £1mn efficiency saving in operating and
capital expenditure retained by the company under different retention
periods

Notes: Using a rate of return/discount rate of 7\%. For operating expenditure, calculations are based on either a recurring or a one off saving of $£ 1 \mathrm{mn}$ per year. For capital expenditure, calculations are based on a either a recurring or a one off saving of $£ 1 \mathrm{mn}$ in a given year, for an asset with an assumed lifetime of 40 years. We also assume that prices are reset to actual costs at the end of the retention period. If the assumed asset life were 20 years then the figure for a one off capital expenditure saving would be $47 \%$ and the figure for a recurring saving would be $13 \%$, assuming a 5 -year retention period.

\section{The role of benchmarking on efficient input use}

This capitalization problem is exacerbated if the benchmarking of operating and capital expenditure is inconsistent. Burns and Davies (1999) highlight a problem

2 The retention period does not need to be equal to the length of the regulatory review cycle, as incentive payments can be structured such that some benefit continues to be retained by the company beyond the regulatory period in which savings are made 
in the regulation of the electricity distribution businesses in Britain. If revenue is allowed on a yardstick basis (unrelated to the firm's own costs) for one expenditure category but set on the basis of the firm's own costs for another, Distribution Network Operators (DNOs) have an incentive to transfer costs from the "yardstick" category to the "firm specific" category.

This is illustrated in Figure 4, where we show two firms, 1 and 2, who both produce the same amount of output, q. Both firms have the flexibility to substitute labor and capital. ${ }^{3}$ We further assume that - at the outset - the regulator allows both firms to charge out their actual cost to customers. Firm 1 is more technically efficient because it is producing the same output as 2 but is using less of both capital and labor to do so. Thus we can say that both firms are allocatively efficient (because both do not charge in excess of cost), but only firm 1 is technically efficient and firm 2 is technically inefficient - its efficiency is given by the ratio $0 \mathrm{~A} / 0 \mathrm{~B}$. Now consider a stylized version of Offer's ${ }^{4}$ regulatory practice in the 1993 price review:

- the regulator decides to allow the firm to recover labor (or operating) costs per unit only up to a yardstick, $\mathrm{L}^{*} / \mathrm{q}$. This reference level is set by the firm which is using the lowest ratio of L/q among all firms observed;

- the regulator signals that he will recognize investment in determining the regulatory asset base - this has the effect of allowing firms to pass through any depreciation and an allowed rate of return on the capital actually employed; and

3 Isocost lines (ICi) illustrate combinations of labor and capital input that result in the same level of unit cost. Curves closer to the origin represent lower levels of cost. The slope of the lines is determined by the factor price of labor relative to capital. The Isoquants illustrate the firms' ability to produce a given level of output with alternative combinations of labor and capital. Isoquants closer to the origin represent lower levels of output. Cost minimizing firms therefore try to be on a low Isocost line and a high Isoquant. It is optimal for each firm to choose a production point where the Isocost line is tangential to a Isoquant. If - in this point - the firmed substituted some labor for capital or some capital for labor, the cost of production would increase for a given level of output.

4 Offer, the Office for Electricity Regulation, was the regulatory agency for the sector from 1989 until 1999, when it was merged with the gas regulator, Ofgas, to create the Office of Gas and Electricity Markets (Ofgem). 
- it monitors both firms to ensure that they have spent up to their regulatory asset base.

\section{Figure 4: Capitalization in response to regulatory signals}

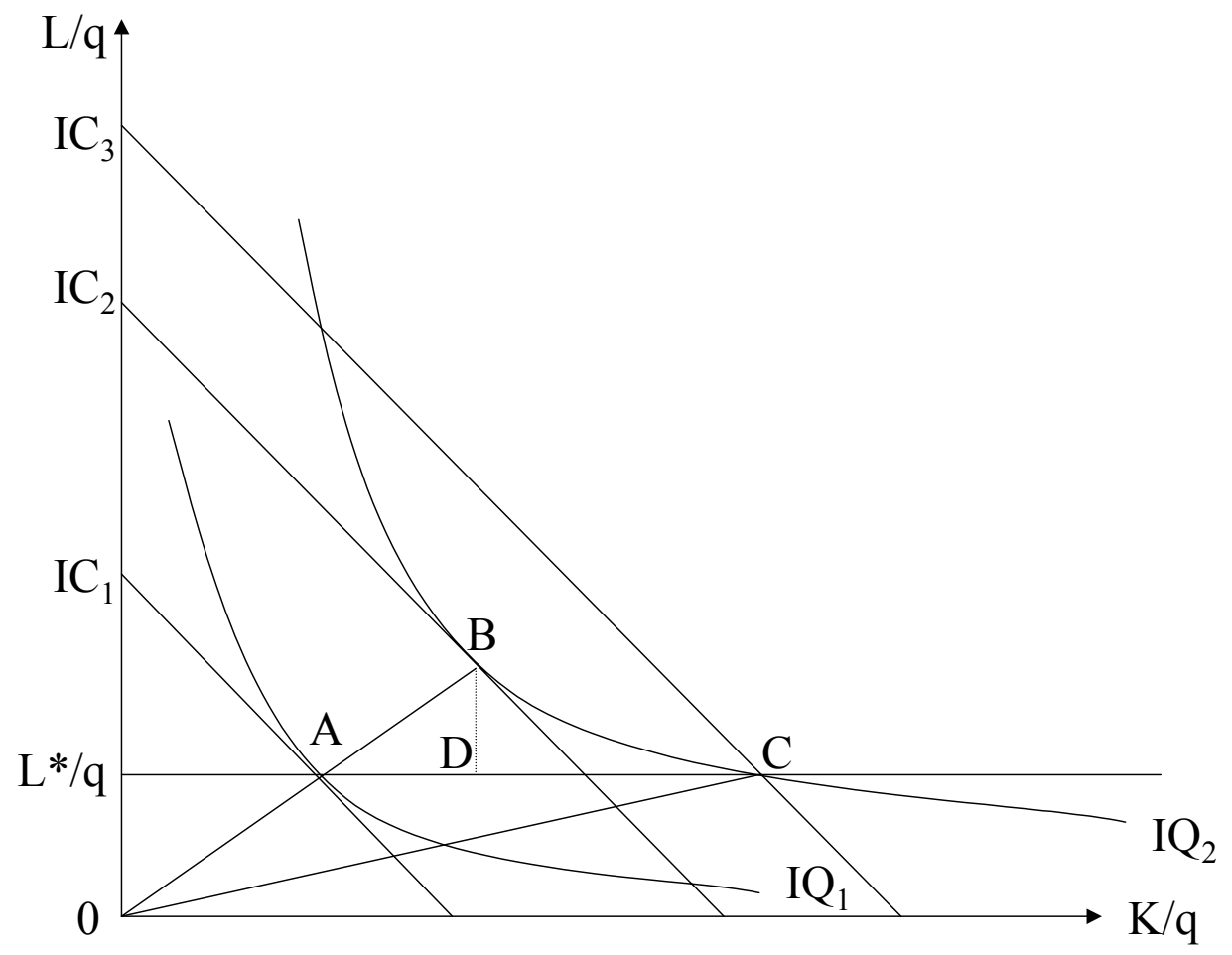

We now look at the effect of company incentives when moving to this regime, e.g. from a previous regime of cost of service regulation (or from price cap regulation). Firm 1's incentives do not change since it had chosen the level of labor input consistent with the benchmark already. ${ }^{5}$ Firm 2 has two options.

Firstly Firm 2 could choose to improve its efficiency by moving to point A in which case it would (have to) increase capital and labor productivity. If this strategy

5 Firm 1 would not have an incentive to deviate from its choice of inputs. For example, if it substituted some capital for labor, it would tighten the benchmark of $\mathrm{L}^{*} / \mathrm{q}$. If on the other hand the labor productivity benchmark was determined exogenously then it may pay for Firm 1 in the way that we describe Firm 2's behavior below. 
required management effort, Firm 2 may discard this option in view of the second alternative.

Secondly it could simply substitute capital for labor by moving to point $\mathrm{C}$ (the point with the lowest level of cost where the company formally meets the labor productivity benchmark), claiming to meet its operating expenditure target $\left(\mathrm{L}^{*} / \mathrm{q}\right)$ and fulfilling its capital expenditure commitments. Firm 2 could arrive at point $\mathrm{C}$ with two different strategies. Either it could re-label some operational expenditure (OPEX, e.g. maintenance activities) as capital expenditure (CAPEX). Alternatively, firm 2 may be able to reduce genuine investment in order to capitalize its operating expenditure. This may not affect the volume of outputs produced, but may adversely affect quality, and the impact would be postponed for some time, then the regulator may not be able to detect a diminution in quality, without the benefit of leading indicators of quality (which at that time Offer did not have). Under either strategy, an ill-informed regulator may be inclined to believe that Firm 2 has become efficient as it meets the labor cost yardstick, particularly, if the measurable outputs appear to have been maintained.

There are three important points to notice from this analysis. First, the inefficient firm has the most incentive to engage in this type of activity (of changing capital to labor ratios in an inefficient manner), since it has most to lose from a reduction in allowable operating costs to $L^{*} / q$. The more efficient the firm, the less incentive it has to substitute capital for labor because it is closer to the benchmark level of operating costs.

Second, the strategy pays off even if the allowed return is well below the true cost of capital. This is because the incentive on the business is to justify a high revenue, and given an inefficient technology not to make a return (although that would be a bonus). The Averch-Johnson effect exists only when the return is greater than the cost of capital. In this case, the inefficient firm has an incentive to gold-plate even if the return is lower than the cost of capital.

Third, if we informally extend this analysis over time, it is obvious that the regulator will create an arbitrary system of rewards and penalties among the businesses if it does not act against this behavior. Put simply, if an inefficient firm 
obtains the same rewards as a more efficient firm, then over time the efficient firms will be less inclined to expend effort to reduce costs, because they can obtain the same rewards by adopting the inefficient businesses' strategy of capitalization.

Finally, thus far, we have concentrated on the case where firm 2 behaves inefficiently by engaging in excessive investment. Our other definition of capitalization is simply where the firm reports a higher level of capital intensity without actually making inefficient decisions. In this case, firm 2 induces no extra inefficiency but simply protects its revenue by hiding its inefficiency through its reporting policy.

In their paper, Burns and Davies provide a number of indicators of capitalization, and at the 2000 distribution price control review, Offer made adjustments to the cost base of the businesses to reflect the capitalization that had occurred, and began work to develop better investment and quality incentives - the Information and Incentives Project (IIP).

\section{Incentive regulation and joint products}

The problem of distortion of inputs can be extended to consider the problem that output provision can be distorted if two outputs that depend on the same costs are subjected to separate regulatory regimes. Where the incentives are balanced, the operator naturally wishes to minimize the total costs of providing both outputs. However, where only one output is subjected to incentive based regulation, it will seek to minimize the costs associated with that output, even if that means the total cost of joint production is not minimized.

The experience of NGC in England and Wales is an interesting case study of the balance of incentives across services. At the privatization of the electricity industry in 1990, National Grid (NGC) was created to own and operate the highvoltage transmission system. In any electricity system, there are certain costs that depend on how well the transmission system is constructed and operated - such as the additional cost of "constrained on" generation (plant required to operate because of transmission constraints) and "ancillary services" (a range of services with no 
common international definition, but essentially relating to paying generators to operate in a manner that assists the operation and security of the system). These costs were recovered as the "transport" component of "uplift" payments, levied on all generators and electricity suppliers (retailers) in the electricity pool.

Initially, NGC simply passed these costs through and therefore received no financial benefit from any action such as network reinforcements that ease congestion on the grid, thus reducing the cost of sub-optimal dispatch of plants ("constrained-on generation" and the need to use additional ancillary services) and the cost of network losses. This was in contrast to other activities undertaken by NGC, notably those associated with the maintenance and development of the network recovered through use of system charges, which were subjected to high-powered incentive regulation. In response to rapid increases in costs, particularly of constrained-on generation, and recognizing that NGC had significant influence over some uplift costs, the regulator introduced an incentive scheme, the Transmission Services Scheme (TSS), first coming into effect in $1994 / 95^{6}$.

The scheme was based on sliding-scale incentive regulation. First, Offer set a target for transmission service costs. Then, if NGC's costs were below this target in any one year, uplift payments were reduced less than proportionately, allowing NGC to retain a proportion of the saving as additional profits. Similarly, if costs exceeded the target, uplift payments increased less then proportionately, exposing NGC to a reduction in profits. A cap on total incentive payments or penalties was established: cost variations beyond the limits implied by this cap were simply passed through onefor-one. The sliding-scale scheme is illustrated in Figure 5 below.

Initially, the scheme specified that NGC retained $30 \%$ of any cost savings (to a maximum of $£ 25 \mathrm{~m}$, about $5 \%$ of the target cost) and paid $20 \%$ of any cost over-run (to a maximum of $£ 15 \mathrm{~m}$ ). Targets were revised annually ${ }^{7}$.

6 In addition, incentives were introduced into the payments made by NGC to the providers of ancillary services, abandoning the previous approach of simple remuneration of cost.

7 Note that sharing ratios and caps changed as the scheme developed. Later schemes also provided for different sharing rules and profit/loss caps for different components of TSS costs. 
The effects on transport uplift costs were impressive, as Figure 6 illustrates. The rapid increases in cost over the first four years of the Pool's existence were reversed. In particular, the "operational outturn" cost category (principally constrained-on generation) fell by more than half comparing the full years before (1993/94) and after (1995/96) the introduction of the scheme.

Figure 5: Allowed revenues and costs under NGC's TSS

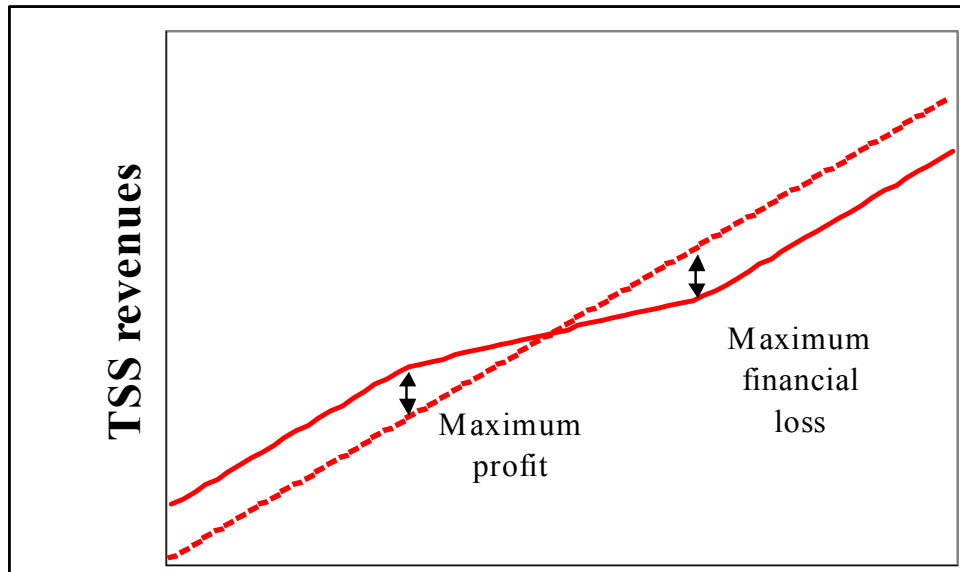

TSS costs 


\section{Figure 6: Uplift costs}

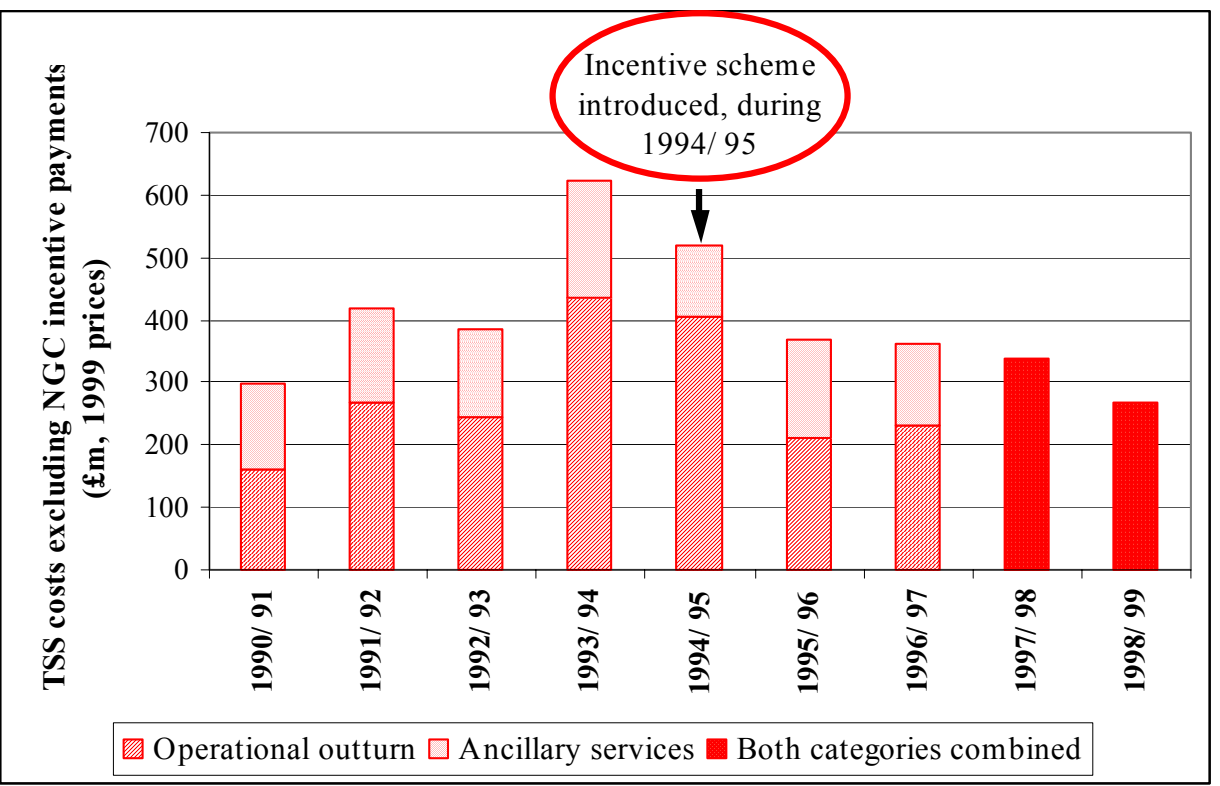

Source: OFGEM documents such as NGC System Operator Incentives, Transmission Access and Losses Under NETA, consultation document (1999), available at http://www.ofgem.gov.uk/temp/ofgem/cache/cmsattach/1447 nsodec.pdf

Clearly, NGC gained substantially from the scheme. The incentive payment in $1994 / 95$ was $£ 22.5 \mathrm{~m}$ and in $1995 / 96 £ 25 \mathrm{~m}$ (in nominal prices which was the maximum allowed payment) ${ }^{8}$. However, the reduction in the two cost categories shown above from $1993 / 94$ to $1995 / 96$ was almost $£ 260 \mathrm{~m}$, about $4 \%$ of the total cost of wholesale electricity in England and Wales. Thus, although NGC might appear to have been the principal beneficiary, the benefits to customers were substantially greater. Furthermore, by exposing its ability to manage these cost categories, NGC provided Offer with information it could use to set tougher targets in the future.

8 It is worth noting that the first payment was below the maximum available while the second was at the maximum. Even in this second year, NGC's performance did not result in costs substantially below the levels at which the maximum payment was triggered. If this had happened, it would be reasonable to conclude that incentives were not the principal driver of the cost reduction. The receipt of two payments close to the maximum suggests (but does not prove) efficient response to incentives on NGC's part. 
Target costs in 1998/99, for example, were only $£ 215 \mathrm{~m}$ - less than half the 1994/95 target.

The scheme was subsequently extended to losses. More generally, Offer (now OFGEM) regarded the scheme as a successful demonstration of the power of slidingscale regulation (see Laffont and Tirole (1993) and Burns, Turvey and Weyman-Jones (1995) for separate analyses of these types of arrangements). For example, OFGEM subsequently introduced sliding scale incentives for the gas pipeline operator, Transco (now part of National Grid Transco) and some seven sliding scale mechanisms apply to different activities.

These regulatory examples can be extended to cover the more general point that for some network businesses - and electricity transmission is a good example the operator needs incentives to minimize the combined cost of transmission and generation (congestion), which does not necessarily mean minimizing the cost of just the transmission activity. For example, in liberalized wholesale electricity markets, interconnectors serve the extremely valuable function of widening a geographic market and consequently weakening the market power of national incumbents. It is important that regulatory arrangements provide the incentive for the network operator to develop interconnector capability, or to increase capacity at certain points on the system if this has the benefit of reducing upstream costs by relieving transmission constraints between regions and countries.

\section{Incentive power and the periodicity effect}

As a result of the cyclical nature of regulatory proceedings, companies retain a greater share of the benefit of cost reductions made early in a regulatory period, rather than later, i.e. the year in which a saving is made in a regulatory review alters the period over which any benefit is retained by the company. This is illustrated in Figure 7 and Figure 8, both of which assume a regulated firm faces a review every 5 years and that no steps are taken to address the periodicity problem. 
Figure 7: Illustration of benefit retained by a regulated company making an efficiency improvement in year 1 of a regulatory period

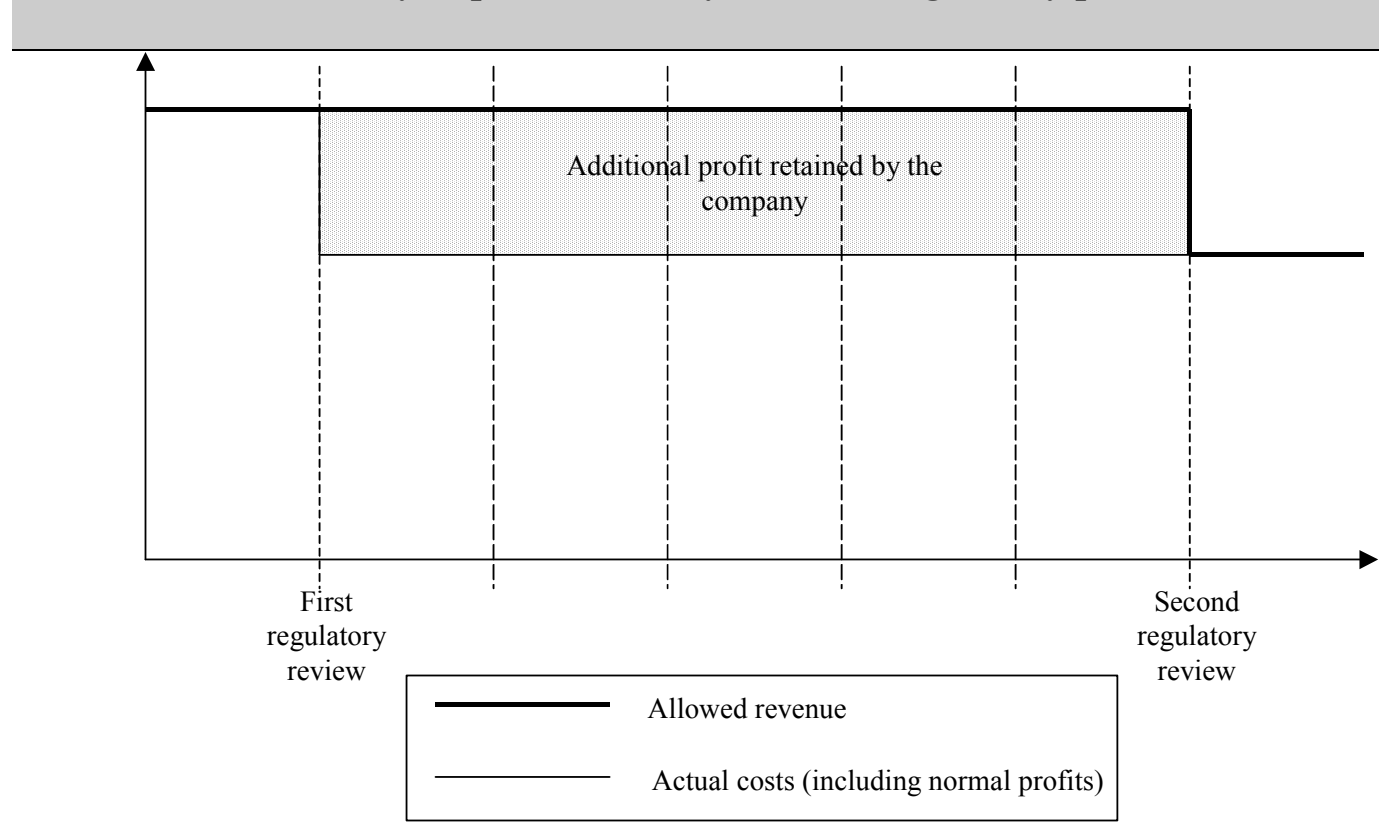

Figure 7 shows the path of costs and revenues for a company that makes an efficiency improvement in the first year of a regulatory period ${ }^{9}$. As a result, the company retains the benefit of this saving for up to five years, before the regulator adjusts its prices at the next review, passing the benefit through to customers. In contrast, Figure 8 shows the path of costs and revenues for a company that makes an efficiency improvement in the fifth and final year of a regulatory period ${ }^{10}$. In this case, the company retains the benefit of the efficiency improvement for at most one year, rather than five. This comparison demonstrates that companies have weaker incentives to make efficiency savings as they progress through a regulatory period. This is likely to have two adverse effects.

9 In practice, this assumes that the company makes the saving on the first day of the first year.

10 In practice, regulatory reviews are often conducted on data pertaining to the penultimate year of a regulatory period as this is typically the timeliest data that is available. This does not alter the principles explained in the discussion above. 
- The timing of cost reductions will be influenced by the regulatory timetable (where companies are not allowed to retain savings for a fixed period of time), rather than the firm's own assessment of its business. Presumably, this will be less efficient than a timetable driven solely consideration of the actual costs and benefits of making an efficiency improvement.

- Variation in incentives encourages "gaming". Cost savings can be delayed, hidden or transferred between years. If successful, gaming is bad for customers because it results in higher prices than necessary. Even if unsuccessful, it increases the difficulty of carrying out regulatory reviews as it makes the assessment of efficient costs more difficult.

Figure 8: Illustration of benefit retained by a regulated company making an efficiency improvement in the final year of a regulatory period

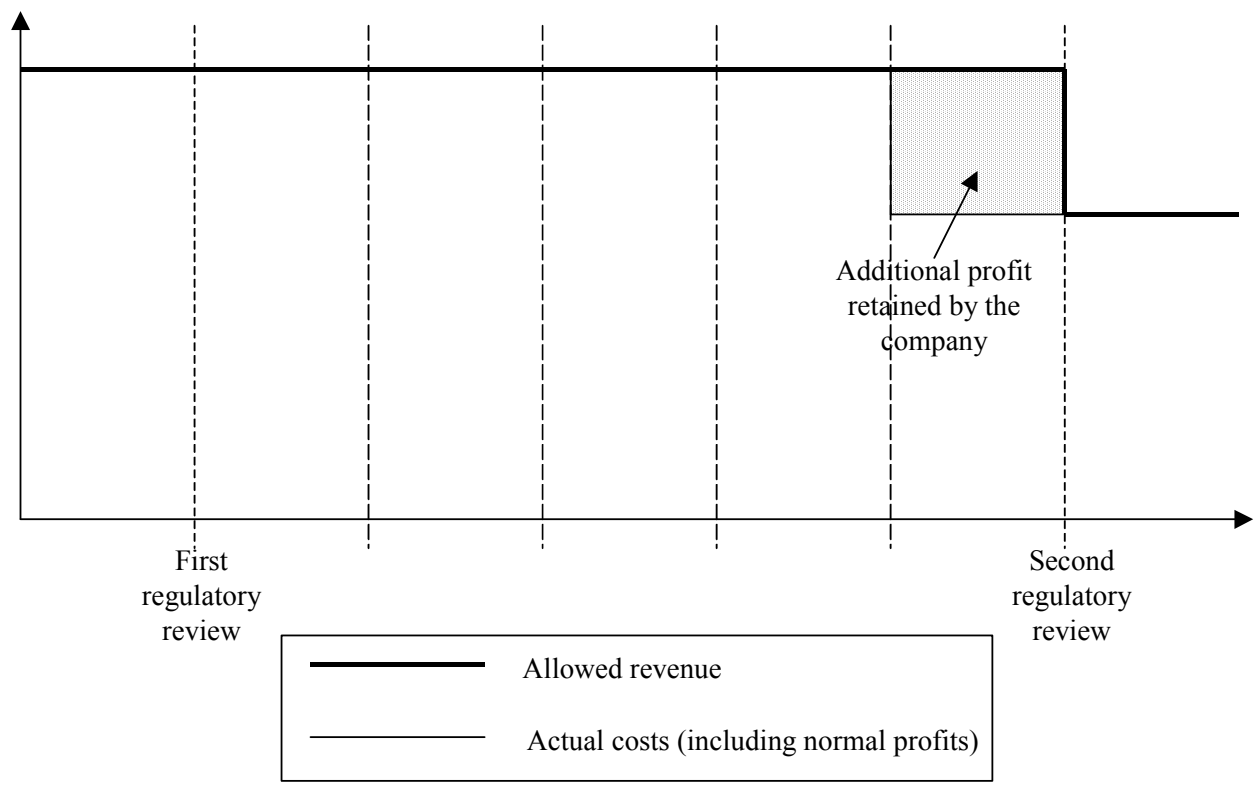

There is some evidence to suggest that regulated companies in a number of sectors have responded to these signals, delaying savings that could be made in the last few years of a regulatory period and making rapid reductions in costs in the years immediately after a review. The table below shows the results of Malmquist productivity analysis undertaken by Frontier Economics. The productivity estimates 
are based upon a model in which the input is cost (either operating or total cost) and the outputs are $\mathrm{kWh}$, maximum demand, number of customers, and proxies for the environment such as the number of transformers and the length of mains. Quite clearly, there was a boost to productivity building up to the first year of the price control that ran between 1995 and 2000, and by 1997/8, which was the last year on which the regulator had data to inform the 2000-2005 price cap, many companies were reporting reductions in productivity. Most of this reflected the reporting of particular costs, that Ofgem were able to unwind, but more generally, it was clear that the companies were saving further cost reductions until after the review. Evidence on cost performance since the review indicates further significant productivity improvement.

\begin{tabular}{|c|c|c|}
\hline \multicolumn{3}{|c|}{ Table 3: Productivity change over time amongst the DNOs } \\
\hline & $\begin{array}{l}\text { Operating expenditure } \\
\text { productivity }\end{array}$ & Total cost productivity \\
\hline $91-92$ & 1.81 & 0.99 \\
\hline $92-93$ & 6.14 & 3.49 \\
\hline 93-94 & 1.36 & 1.66 \\
\hline 94-95 & 3.67 & 1.65 \\
\hline 95-96* & 27.59 & 13.7 \\
\hline 96-97 & 7.07 & 2.82 \\
\hline $97-98 * *$ & -7.72 & -4.19 \\
\hline $91-98$ & 4.85 & 2.66 \\
\hline 92-88 & 5.4 & 2.95 \\
\hline
\end{tabular}

\section{Lessons for regulators}

In the previous sections of this report, we have outlined how regulatory instruments can affect investment and output delivery in an incentive based regulatory model. In doing so, we hope to have shown that what falls under the general label of incentive based regulation can, depending upon how the parameters of the regime are 
set, induce too much or too little investment; too much or too little output provision; distort input usage; and distort the timing of investment spending and efficiency gains more generally.

In a sense this is unsurprising. Regulation is a problem of asymmetric information and setting the parameters of the regulatory system is unlikely to result in both an optimal level of cost and service quality. However, through appropriate regulatory design and collection and monitoring of relevant cost and asset data, it should be possible to at least avoid some of the worst imbalances in incentive packages. These imbalances come at a welfare cost and a distributional cost. The welfare cost arises through the inappropriate use of resources. The distributional effect arises because the essence of incentive based regulation is that companies must be induced to reveal information or elicit effort through the provision of profit incentives. If the wrong incentives are put in place, then payment is made for information of no value, a cost that falls directly upon the consumer. Consequently, the quality of the incentive regime is not an abstract matter, but one of significant economic importance.

\section{Output based regulation should form the basis for the incentive regime}

It is important to begin by establishing that output-based regulation is the appropriate basis for the incentive regime. In general, businesses exist to provide services to customers. They do not exist to incur costs, although of course that is a natural consequence of service provision. Regulated businesses are no different in this respect to other businesses.

Moreover it is also true that in general if the price of the output increases, the firm is induced to supply more of it, and vice versa. For a regulated business, there must be a financial incentive to continue to provide outputs, and this incentive exists through a number of mechanisms - through explicit quality regimes as well as through the price control determination process. Consequently, an output based regime mimics, to some extent, the value for money offering made by firms in competitive markets. 
The counterfactual case is one where regulation is input based, that is firms are rewarded for the inputs they use, either directly, or because an input (e.g. investment) is used as a proxy for output. If the value of investment incentives increases with the amount of investment undertaken, the consequence will be high levels of inefficiency. It is also questionable whether quality would increase in such a scheme because only inputs, not outputs would be monitored.

\section{The freedom the firm has to choose its level of output can be limited by regulatory instruments}

Even though the incentive regime should be output based, this does not necessarily mean that the firm should be given unfettered choice over the level of service provision. This approach was effectively adopted in the rail sector in Britain to disastrous effect. Instead the regulator can choose a mixture of price and non-price incentives to ensure that output provision is locked in to some socially acceptable range. The focus of the incentive regime shifts to the minimization of costs, subject to that output range being met.

\section{Output based regulation requires a proper definition of outputs}

Part of the reason why quality regulation is so under-developed, and the experience has been so mixed, is because the quality indicators have not been available. As a consequence of the problems of using investment as an indicator of quality however, some regulators (e.g. Ofgem in Britain) are beginning to assess whether quality indicators can be developed. The difficulty, as noted earlier is that quality indicators should not just measure current output performance, but also expected future output performance given the quality of the assets in place.

Consequently, regulators need to work harder to establish these indicators of performance. Having done so, different regulatory instruments can be applied to different types of information. For example, it may be possible to apply marginal payment schemes to some easily measurable outputs (e.g. minutes of electric power lost) within a cap and collar scheme, but if the interpretation of an asset report is more subjective, then it should be dealt with under non-price mechanisms. The point is that 
the regulated business is reminded of its obligations to ensure continued output provision into the longer term. A number of approaches exist to allow the regulator to critically assess the information it has been presented with, including independent audit examinations, shadow network modelling and so forth.

As regulation evolves from its focus on cost minimization to one of network integrity and output delivery, the proper definition of outputs that can form the basis of incentive regulation is the major task ahead for regulators and companies.

\section{If a comparative incentive regime is used, it should not apply to both costs and service provision, but only to one of these}

Yardstick competition has significant efficiency benefits, but the application of a yardstick mechanism to both costs and quality leads to an inherent circularity in the regulatory arrangements, and multiple equilibria. In these situations, regulators should focus on whether they wish to promote cost reduction, subject to quality safeguards that cannot be breached, or quality enhancement on a comparative basis, with costs determined as a residual. In our view, the former approach is likely to be less complex to administer, provides clarity to companies and yet at the same time provides the necessary safeguards on output provision.

\section{Incentive based regulation should avoid distortion of the firm's input choices}

Regulators should seek to evaluate and reward operating and capital efficiency on the same basis in order to avoid distorting input use. One way of doing this is to develop a total cost model of the businesses to be benchmarked, and uprate prices on the basis of total costs. The construction of a total cost variable has been described in Frontier Economics (2003)

\section{Regulation should promote balanced incentives across different regulated products}

This should ensure that total cost is minimized, not just the cost of producing the output with the highest-powered regulation. 


\section{Regulation should promote balanced incentives over time}

In order to avoid companies distorting the timing of efficiency gains, the regulatory regime should ensure that the NPV of any efficiency gain is the same irrespective of when in the regulatory cycle it is made. Such an approach has been adopted by the water regulator in England and Wales.

\section{Conclusions}

With the introduction of high-powered incentive regimes attention needs to be paid to the development of investment. Quite often, historic and low-powered incentive regimes contained an inherent incentive to over-invest. Incentive regulation that ignores investment or at least the quality of supply could lead to a deterioration of service quality. While this has not yet become an issue in industries where there is initially overcapacity and where there are long asset lives, there have been problems in implementing incentive regulation where the initial starting point was an already weak infrastructure.

This paper has demonstrated that the design of incentive mechanisms to promote efficient investment behavior is by no means straightforward, and inadequate attention to the problem can result in serious distortions and problems. The key lesson

from this paper is that the construction of the package of incentives should be approached with care, and must be accompanied by the development and effective monitoring of meaningful output indicators. 


\section{REFERENCES}

Averch, H., and L.L. Johnson, 'Behavior of the firm under regulatory constraint', 1962, American Economic Review, 52, pp 1056-69

Baumol, W. and P. Kleverick, 1970, 'Input choices and rate of return regulation: an overview of the discussion'. Bell Journal of Economics and Management Science.

Burns, P., and J. Davies, 1998, Regulatory incentives and capital efficiency in UK electricity distribution businesses, CRI Technical Paper No. 12.

Burns, P., R. Turvey, and T.G. Weyman-Jones ,1998, Behavior of the Firm under Alternative Regulatory Constraints, Scottish Journal of Political Economy

Frontier Economics, 2003, Balancing Incentives. A report for Ofgem

Frontier Economics, 2003, Dealing with uncertainty. A report for Ofgem.

Laffont, J.-J. and J. Tirole (1993), A Theory of Incentives in Procurement and Regulation. MIT Press.

National Audit Office, 2002, Pipes and Wires.

Ofgem, NGC System Operator Incentive Scheme 2003/04 - 2005/06: Initial Consultation Document, 68/02, 18 October 2002. 